\title{
A B BREVIATIONS
}

ABIA Associação Brasileira Interdisciplinar de AIDs /

Brazilian Interdisciplinary AIDS Association

AI-5 Ato Institucional Número 5 / Institutional Act No. 5

ALN Ação Libertadora Nacional / National Liberating Action

AP Ação Popular / Popular Action

ARENA Aliança Renovadora Nacional / National

Renovating Alliance

свA Comitê Brasileiro de Anistia / Brazilian

Amnesty Committee

CEM Centro de Estudos de Medicina / Center for the Study of Medicine

COLINA Comandos de Libertação Nacional / National

Liberation Commandos

Cosec Comando de Estudantes Secundaristas / High School Students' Command

DCE Diretório Central de Estudantes / Central

Student Directorate 
DDD Dissidência da Dissidência / Dissidence of the Dissidence

DVP Dissidência de var-Palmares / var-Palmares

Dissidence

FHAR Front Homosexuel d'Action Révolutionnaire /

Homosexual Front for Revolutionary Action

GAPA Grupo de Apoio à Prevenção à AIDs / Support Group for AIDs Prevention

GGB Grupo Gay da Bahia / Gay Group of Bahia

GLH-P\&Q Groupe de Libération Homosexuelle-Politique et Quotidien / Homosexual Liberation Group-Politics and Daily Life

GPV Grupo Pela vidda (Valorização, Integração, e Dignidade do Doente de AIDs) / Pela vidDa Group (The Valuing, Integration, and Dignity of Those Sick with AIDs)

MDB Movimento Democrático Brasileiro / Brazilian Democratic Movement

MFA Movimento das Forças Armadas / Movement of the Armed Forces

MNR Movimento Nacional Revolucionário / National Revolutionary Movement

MR-8 Movimento Revolucionário 8 de Outubro / October 8th Revolutionary Movement

MRP Movimento de Resistencia Popular / Movement of Popular Resistance

MRT Movimento Revolucionário Tiradentes / Tiradentes Revolutionary Movement 
PCB Partido Comunista Brasileira / Brazilian Communist Party

PDS Partido Democrático Social / Social Democratic Party

PDT Partido Democrático Trabalhista / Democratic Labor Party

PMDB Partido do Movimento Democrático Brasileiro / Party of the Brazilian Democratic Movement

POLOP Organização Revolucionária Marxista-Política Operária / Revolutionary Marxist OrganizationWorkers' Politics

PT Partido dos Trabalhadores / Workers' Party

ртв Partido Trabalhista Brasileira / Brazilian Labor Party

PV Partido Verde / Green Party

REDE Resistência Democrática / Democratic Resistance

somos Somos: Grupo de Afirmação Homossexual / We Are:

Group of Homosexual Affirmation

UfMG Universidade Federal de Minas Gerais / Federal

University of Minas Gerais

UNE União Nacional de Estudantes / National Union of Students

VAR-Palmares Vanguarda Armada Revolucionária-Palmares / Revolutionary Armed Vanguard-Palmares

VPR Vanguarda Popular Revolucionária / People's

Revolutionary Vanguard 
This page intentionally left blank 